\section{FRI0452 TOFACITINIB IN PATIENTS WITH PSORIATIC ARTHRITIS: ANALYSIS OF DERMATOLOGIC ENDPOINTS FROM 2 PHASE 3 STUDIES}

Joseph F. Merola ${ }^{1}$, Kim Papp ${ }^{2}$, Peter Nash ${ }^{3}$, Jordi Gratacos-Masmitja ${ }^{4}$, WolfHenning Boehncke ${ }^{5}$, Diamant Thaçi ${ }^{6}$, Daniela Graham ${ }^{7}$, Ming-Ann Hsu ${ }^{7}$, Cunshan Wang ${ }^{7}$, Joseph Wu ${ }^{7}$, Pamela Young ${ }^{8}$. ${ }^{1}$ Brigham and Women's Hospital, Harvard Medical School, Boston, MA, United States of America; ${ }^{2}$ Probity Medical Research and K Papp Clinical Research Inc, Waterloo, ON, Canada; ${ }^{3}$ University of Queensland, Brisbane, Australia; ${ }^{4}$ Servicio de Reumatología, Hospital Universitari Parc Taulí Sabadell, Barcelona, Spain; ${ }^{5}$ Geneva University Hospital, University of Geneva, Geneva, Switzerland; ${ }^{6}$ Institute and Comprehensive Center for Inflammation Medicine, University of Lübeck, Lübeck, Germany, ${ }^{7}$ Pfizer Inc, Groton, CT, United States of America; ${ }^{8}$ Pfizer Inc, Collegeville, PA, United States of America

Background: Psoriatic arthritis (PsA) is a chronic, systemic inflammatory disease; the onset of dermatologic symptoms often precedes rheumatic manifestations. ${ }^{1}$ Tofacitinib is an oral Janus kinase inhibitor for the treatment of PsA. It has been shown that tofacitinib can improve dermatologic symptoms in patients (pts) with PsA. ${ }^{2,3}$

Objectives: To investigate the efficacy of tofacitinib in improving additional dermatologic endpoints in adult pts with active PsA.

Methods: This analysis included data from 2 placebo (PBO)-controlled, double-blind, Phase 3 studies in pts with active PsA and an inadequate response (IR) to $\geq 1$ conventional synthetic disease-modifying antirheumatic drug (csDMARD) who were tumour necrosis factor inhibitor (TNFi)-naïve (OPAL Broaden [12 months; NCT01877668]; $\mathrm{N}=422)^{2}$ or had an IR to $\geq 1$ TNFi (OPAL Beyond [6 months; NCT01882439]; N=394). ${ }^{3}$ Pts must have had active plaque psoriasis at screening only and were required to receive a stable dose of 1 csDMARD. Pts were randomised to tofacitinib $5 \mathrm{mg}$ twice daily (BID), $10 \mathrm{mg}$ BID, adalimumab $40 \mathrm{mg}$ subcutaneous injection once every 2 weeks (OPAL Broaden only) or PBO (advanced to tofacitinib 5 or $10 \mathrm{mg} \mathrm{BID}$ at Month [M]3). Percentage (\%) change from baseline $(\mathrm{BL})(\Delta)$ in Psoriasis Area and Severity Index (PASI) total score, $\%$ of pts achieving $\geq 75 \%$ PASI improvement from BL (PASI75) stratified by BL PASI severity $(>0$ to $\leq 10$, or $>10)$, and $\triangle$ Patient's Global Joint and Skin Assessment-Visual Analogue Scale Psoriasis question (PGJSVAS Psoriasis) were measured at M1, 3, 6, and at M9 and 12 (OPAL Broaden only).\% $\triangle \mathrm{PASI}$ total score and PASI75 were measured only in pts with $B L$ affected body surface area (BSA) $\geq 3 \%$ and PASI $>0$. Safety endpoints were also analysed.

Results: BL demographics were similar between treatment groups and studies. BL median PASI scores (pts with $\mathrm{BL}$ BSA $\geq 3 \%$ and PASI $>0$ ) ranged from 5.6 to 7.8 (OPAL Broaden) and 7.1 to 8.8 (OPAL Beyond). BL mean PGJS-VAS Psoriasis ranged from 51.0 to 54.8 (OPAL Broaden) and 53.5 to 58.9 (OPAL Beyond). At M1 and 3,\% $\triangle \mathrm{PASI}$ total score, PASI75 response rates in pts with mild or moderate/severe dermatologic symptoms at $\mathrm{BL}$, and $\triangle \mathrm{PGJS}-\mathrm{VAS}$ Psoriasis were improved vs PBO in tofacitinib-treated pts; these improvements were maintained to M12 in OPAL Broaden and M6 in OPAL Beyond (Table). Similar effects were observed in adalimumab-treated pts vs PBO in OPAL Broaden across these endpoints. Serious adverse events (AEs) and discontinuations due to AEs were similar across treatment groups up to $M 6$ in OPAL Beyond and M12 in OPAL Broaden.

Conclusion: In pts with PsA (TNFi-naïve or TNFi-IR), tofacitinib improved dermatologic endpoints, and responses were maintained to the end of each study. Tofacitinib may provide a treatment option for pts with active PsA, including the dermatologic symptoms of PsA.

\section{REFERENCES:}

[1] Gladman DD, et al. Ann Rheum Dis 2005;64:ii14-7.

[2] Mease P, et al. N Engl J Med 2017;377:1537-50.

[3] Gladman D, et al. N Engl J Med 2017;377:1525-36.

Acknowledgement: This study was sponsored by Pfizer Inc. Medical writing support was provided by Mark Bennett, PhD, of CMC Connect, a division of McCann Health Medical Communications Ltd, Manchester, UK, and was funded by Pfizer Inc.

Disclosure of Interests: Joseph F. Merola Consultant for: Biogen IDEC, Abbvie, Amgen, Eli Lilly and Company, Novartis, Pfizer, Janssen, UCB, Samumed, Celgene, Sanofi Regeneron, Merck, and GSK, Kim Papp Grant/research support from: AbbVie, Akros, Allergan, Amgen, Anacor, Arcutis, Astellas, Baxalta, Boehringer Ingelheim, Bristol-Myers Squibb,
Can-Fite, Celgene, Coherus, Dermira, Dow Pharma, Eli Lilly, Galderma, Genentech, Gilead, GlaxoSmithKline, InflaRx GmbH, Janssen, Kyowa Hakko Kirin, Leo, Medlmmune, Merck (MSD), Merck Serono, Moberg Pharma, Novartis, Pfizer, PRCL Research, Regeneron, Roche, SanofiAventis/Genzyme, Takeda, UCB, Valeant/Bausch Health, Consultant for: AbbVie, Akros, Amgen, Arcutis, Astellas, AstraZeneca, Baxalta, Baxter, Boehringer Ingelheim, Bristol-Myers Squibb, Can-Fite, Celgene, Coherus, Dermira, Dow Pharma, Eli Lilly, Forward Pharma, Galderma, Genentech, Janssen, Kyowa Hakko Kirin, Leo, Meiji Seika Pharma, Merck (MSD), Merck Serono, Mitsubishi Pharma, Novartis, Pfizer, PRCL Research, Regeneron, Roche, Sanofi-Aventis/Genzyme, Takeda, UCB, Valeant/ Bausch Health; honoraria: AbbVie, Akros, Amgen, Baxter, Boehringer Ingelheim, Celgene, Coherus, Eli Lilly, Forward Pharma, Galderma, Janssen, Kyowa Hakko Kirin, Merck (MSD), Merck Serono, Mitsubishi Pharma, Novartis, Pfizer, PRCL Research, Sanofi-Aventis/Genzyme, Takeda, UCB, Valeant/Bausch Health; steering committee: AbbVie, Amgen, Boehringer Ingelheim, Celgene, Eli Lilly, Janssen, Kyowa Hakko Kirin, Merck (MSD), Merck Serono, Novartis, Pfizer, Regeneron, Sanofi-Aventis/Genzyme, Valeant/Bausch Health; advisory boards: AbbVie, Amgen, Astellas, Baxter Boehringer Ingelheim, Bristol-Myers Squibb, Celgene, Dow Pharma, Eli Lilly, Galderma, Janssen, Merck (MSD) Novartis, Pfizer, Regeneron, Sanofi-Aventis/Genzyme, UCB, Valeant/Bausch Health, Speakers bureau: AbbVie, Amgen, Astellas, Celgene, Eli Lilly, Galderma, Janssen, Kyowa Hakko Kirin, Leo, Merck (MSD), Novartis, Pfizer, Sanofi-Aventis/Genzyme, Valeant/Bausch Health; scientific officer: Akros, Anacor, Kyowa Hakko Kirin, Peter Nash Grant/research support from: AbbVie, Bristol-Myers Squibb, Eli Lilly, Janssen, Novartis, Pfizer Inc, Roche, Sanofi, UCB, Consultant for: AbbVie, Bristol-Myers Squibb, Eli Lilly, Janssen, Novartis, Pfizer Inc, Roche, Sanofi, UCB, Speakers bureau: AbbVie, Bristol-Myers Squibb, Eli Lilly, Janssen, Novartis, Pfizer Inc, Roche, Sanofi, UCB, Jordi Gratacos-Masmitja Grant/research support from: Pfizer Inc, Consultant for: Pfizer Inc, Speakers bureau: Pfizer Inc, Wolf-Henning Boehncke Consultant for: Pfizer Inc, Speakers bureau: Pfizer Inc, Diamant Thaçi Grant/ research support from: AbbVie, Almirall, Amgen, Bio Skin, Biogen-Idec, Boehringer Ingelheim, Bristol-Myers Squibb, Celgene, Chugai, Dermira, Dignity, Eli Lilly, Forward Pharma, GlaxoSmithKline, Janssen Cilag, Leo Pharma, Novartis, Pfizer, Regeneron, Roche, Sandoz-Hexal, Sanofi, and UCB, Consultant for: AbbVie, Almirall, Bristol-Myers Squibb, Celgene, Dignity, Galapagos, Leo Pharma, Lilly, Novartis, Pfizer, and UCB; honoraria: AbbVie, Almirall, Amgen, Bio Skin, Celgene, Dignity, Janssen, Leo Pharma, Merck Sharp \& Dohme, Novartis, Pfizer, Roche-Posay, SandozHexal, Sanofi, and USB; advisory board: AbbVie, Bio Skin, Bristol-Myers Squibb, Celgene, Dignity, Eli Lilly, Galapagos, GlaxoSmithKline, Janssen Cilag, Leo Pharma, Morphosis, Novartis, Pfizer, Sandoz, Sanofi, and UCB, Daniela Graham Shareholder of: Pfizer Inc, Employee of: Pfizer Inc, Ming-Ann Hsu Shareholder of: Pfizer Inc, Employee of: Pfizer Inc Cunshan Wang Shareholder of: Pfizer Inc, Employee of: Pfizer Inc, Joseph Wu Shareholder of: Pfizer Inc, Employee of: Pfizer Inc, Pamela Young Shareholder of: Pfizer Inc, Employee of: Pfizer Inc DOI: 10.1136/annrheumdis-2019-eular.798



